\title{
Views of Nursing Students Who Have Experienced Caring for Psychiatric Patients on Mental Illness and Stigma: A Phenomenological Study

\author{
Ceyda Başoğul, RN, PhD*
}

Assistant Professor, Department of Psychiatric Nursing, Faculty of Health Sciences, Adiyaman University, Turkey

*Corresponding author: Ceyda Başoğul, RN, PhD, Assistant Professor, Department of Psychiatric Nursing, Faculty of Health Sciences, Adiyaman University, Altinşehir Mahallesi, 3005 Street No: 13, Adiyaman, 02040, Turkey, Tel: 0416-2233800 Extension: 4628

\begin{abstract}
Aim: To explore the views of nursing students who have experienced caring for psychiatric patients on mental illness and stigma.

Methods: The phenomenological method was used in the study as the qualitative research design. The research was conducted with 23 students who completed the theoretical part of the psychiatric nursing course and its clinical practice in the nursing department of a university in Turkey. The data were collected through individual in-depth interviews and analyzed by content analysis method.
\end{abstract}

Results: In this study, the research efforts were continued until data saturation was achieved, and in this respect, the data saturation was attained with 23 students. Upon the analysis of research data, five main themes and 12 subthemes were developed. The main themes were as follows: (1) Meaning of mental illness, (2) Challenges experienced by the patients, (3) Reasons for stigmatization, (4) Recommendations for reducing the stigmatization, and (5) Effect of psychiatric nursing course.

Conclusion: It was identified that the nursing students shared common views about the reasons for the stigmatization and the recommendations for reducing it, and the psychiatric nursing course gave rise to positive changes in students' emotions, thoughts, and behaviors about the mental illnesses.

\section{Keywords}

Mental disorder, Nursing student, Psychiatric nursing, Stigmatization

\section{Introduction}

Mental illnesses can be devastating for the individuals not only because of the clinical symptoms and indications of the illness but also due to the problems which come into play at the personal and family levels within the social framework [1,2]. Also, the individuals diagnosed with mental illnesses get frequently exposed to stigmatization across the society in general, in their families and among their kinfolks, in terms of their relations with health workers and even between themselves [3]. Stigma is defined by the World Health Organization as a 'mark of shame, disgrace, or disapproval' [4]. 'Being rejected, being exposed to discrimination, and being excluded from participating in certain different realms of the society' are among the negative consequences of the stigmatizing attitudes. The stigmatization does not only affect the psychological well-being and development of the persons with mental disorders, but it also acts as a crucial obstacle preventing them from seeking, accessing, and continuing the treatment [5].

So that the patients can be reintegrated into society upon recovery from the mental illness, the need arises for cooperation with the authorities which include the local governments as well. It is considered that the nurses will have a crucial place in this area as it is a multidisciplinary service (medical doctor, nurse, patient, patient's relative, head of neighborhood government, and so on.) [3]. Healthcare providers who exhibit posi-

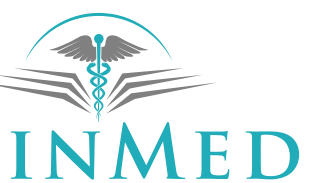

INTERNATIONAL LIBRARY

Citation: Başoğul C (2021) Views of Nursing Students Who Have Experienced Caring for Psychiatric Patients on Mental Illness and Stigma: A Phenomenological Study. Int Arch Nurs Health Care 7:158. doi.org/10.23937/2469-5823/1510158

Accepted: May 13, 2021: Published: May 15, 2021

Copyright: (c) 2021 Başoğul C. This is an open-access article distributed under the terms of the Creative Commons Attribution License, which permits unrestricted use, distribution, and reproduction in any medium, provided the original author and source are credited. 
tive attitudes towards individuals with mental disorders can help to improve the outcomes of the treatment [6]. However, an edited collection that explored the studies performed in Turkey for the last decade demonstrated that the repudiative and exclusionary attitudes of nursing students and health workers toward psychiatric patients did not change [7].The studies carried out across the world show that health professionals utilize definitions such as dangerous and unpredictable concerning the patients with mental disorders although they do so to a lesser extent than society does [8-11].

The positive or negative beliefs which are developed by the health professionals toward the psychiatric patients and the mental illnesses affect the quality of healthcare offered to the patients $[6,12]$. The negative attitudes toward the patients prevent the nurses from developing therapeutic relations with the patients and affect their defensive roles in reducing stigma [13]. Thus, nursing education plays a big role in shaping nursing students' attitudes toward people with mental disorders [14] and can shape these negative attitudes in a positive direction [3].

Currently, there is a limited number of evidence about nursing students' views on mental illnesses and the effects of the theoretical part of the psychiatric nursing course and its clinical practices. Analyzing how nursing students perceive mental illnesses and exploring their views and recommendations about these illnesses and stigmatization are of utmost importance to the improvement of the nursing education of the future [15]. Undergraduate nursing students have theoretical education on mental illnesses and have the opportunity to get in touch with the patients and to develop a therapeutic relationship with them in the areas of psychiatry practice. Examining the views of these students about the mental illnesses, the challenges experienced by the patients, and the stigmatization will help to shape the nursing education of the future.

\section{Methods}

\section{Study design}

By using a qualitative phenomenological approach, this study was performed for examining what views the nursing students who completed the theoretical part of the psychiatric nursing course and its clinical practice had about mental disorders and stigmatization. Phenomenological research which is based on the individual's experience and aspires to interpret the societal phenomena built on the experiences which the individual actually had is a powerful qualitative research design which is frequently used in particular in sociology and a variety of disciplines such as health sciences, psychology and education [16]. The research was reported in conformity with 'Consolidated Criteria for Reporting Qualitative Research (COREQ)' [17].

\section{Setting and sample}

The research population is comprised of 72 fourthyear nursing students enrolled in the nursing department of a university in Turkey in 2019. Purposive sampling, a qualitative sampling method, was employed in the selection of the research sample. It is asserted that the depth and breadth of the data to be obtained from the qualitative research should be inversely proportional to the sample size [18]. The following served as the inclusion criteria: (a) Being enrolled in the nursing department of the health sciences faculty where the research was conducted, (b) Completing the theoretical part of the psychiatric nursing course and its practice, (c) Being open to communication and cooperation, and (d) Volunteering to take part in the study. The psychiatric nursing course is composed of 84 hours of theory in the nursing department of a university and practice to be performed in the public mental health center and the psychiatric clinic of a university hospital. This course aims to determine the mental needs of the individual, family and society by using psychiatric nursing knowledge, skills and therapeutic communication techniques, and to examine human behaviors and mental disorders and it covers the principles, function and process of basic psychiatric nursing. The course was given by a faculty member who completed her doctorate in this field and was completed in about three months. Some topics of the course; definition of mental health and disorder, history of psychiatry, stigma, diagnosis and classification of mental disorders, psychiatric symptoms and signs, assessment of psychiatric patient, observation, interview, nursing approach to patients with schizophrenia and other psychotic disorders, anxiety disorders, mood disorders, substance use disorders, personality disorders, treatment models in psychiatry, therapeutic setting, consultation-liaison psychiatry services, community mental health services. The interviews were held until the data saturation was achieved. In this regard, the data saturation was attained with 23 participants. In the process of reporting, the participant nursing students were codenamed as S1, S2, S3, ..., S23.

\section{Measurements}

The research data were collected via in-depth interview by using 'Personal Information Form' and 'Semi-Structured Interview Form' which were prepared by the researchers. In the literature review, the SPIDER (Sample, Phenomenon of Interest, Design, Evaluation, Research Type) search tool which was well-suited to the qualitative research studies was employed [19].

Personal information form: The form contains seven questions which are created by the researchers based on the relevant literature and pertain to the participant nursing students' sociodemographic characteristics, their psychiatric examination and therapy histories, whether they visit a psychiatrist or psychologist upon 
Table 1: Questions of the semi-structured interview form.

1. Can you describe the concept of mental illness with one word?

2. According to you, what are the challenges experienced in society by individuals with mental illnesses? Can you explain them?

3. What are the factors giving rise to the stigmatization of individuals with mental disorders?

4. How can the stigmatization be coped with? What do you recommend on this issue?

5. How did the psychiatric nursing course affect you on this issue? Can you explain it?

having a mental problem, and the mental disorder histories of their families.

Semi-structured interview form: This form is comprised of five open-ended questions designed to explore the participant nursing students' views on the mental disorder and stigmatization (Table 1). Opinions and views on the questions were received from two experts in the area of nursing.

\section{Data Collection}

First, information on the purpose of the study and how the study would be performed was given to the nursing students, and then the students were invited to partake in the study. Research data were collected via in-depth interviews. Data on the individuals' experiences, emotions, views, and beliefs can be gathered through in-depth interviews [20]. The interviews were held face-to-face with the participants by the interviewer. All interviews were recorded with a digital audio recorder after getting verbal permission from the participants. In the interview, a semi-structured interview form was employed. Through the previously-prepared open-ended questions and the questions raised during the interview, the semi-structured interview enables the researcher to address all details about the problem which is under consideration [20]. The questions in the interview form were directed to each student in the same sequence and manner. The timetable for the interviews was designated as per the preferences of the participant nursing students. The interviews took place in a convenient, quiet, and well-lit meeting room. Having uninterrupted interviews was ensured so that the participant nursing students could express themselves better. Likewise, efforts were made to assure that the process of listening to the participants took place actively and objectively during the interviews. The interviews took around $30-45$ minutes. The data collection process was continued until similar concepts were set forth by the participants, in other words, until the data saturation was attained. Data saturation is the point where the researcher no longer acquires a new perspective, no new information, and the obtained information begins to repeat each other. The saturation criterion for putting an end to the interviews was designated as the point where no new theme emerged after the next three interviews.

\section{Data Analysis}

The analysis of research data was put in place after the process of data collection. After the audio records were transcribed into the texts, the researcher read them a few times for evaluation. The data obtained from the interviews were evaluated via the inductive content analysis method. The content analysis is to analyze the content of statements by examining the words, themes, and idioms within one or multiple texts. The responses given by the participant students were analyzed, and hence the codes were created. The encoded data were assigned to sub-themes by taking their differences and similarities into consideration. Finally, after the sub-themes were integrated, the main themes were created. After the main themes and sub-themes were designated, they were compared and contrasted to the participant students' statements and their responses to the questions created in the context of the study. The research data were categorized under these themes [18].

Moreover, the credibility, transferability, coherence, objectivity, and confirmability strategies were put in place for ensuring the validity and reliability of the research [21]. In order to increase the external reliability of the research, all data collection tools, raw data, coding made during the analysis phase and the perceptions that form the basis of the report were presented to an external expert for the examination of a confirmation. The researcher and an expert experienced in qualitative research also performed coding separately and the codings were compared. The reliability formula (Reliability $=$ Consensus $/($ Consensus + Disagreement $) \times 100)$ proposed by Miles and Huberman (1994) was used to calculate the reliability of the study [22]. As a result of the analysis, the reliability rate was found to be $91 \%$. In order to increase the internal reliability of the research, all of the findings are given directly without comment. In the process of qualitative data analysis, computer algorithms were not utilized. In the planning, data collection, analysis, and reporting stages of the study, the Turkish language was used, and the text was later translated into English. For the control of translation, a back-translation method was utilized.

\section{Ethical Consideration}

At the beginning of the interview, the purpose of the interview was explained to the student nurses, and also the nursing students were informed that the confidentiality of their names and the data obtained under the research would be protected. The permission for the 
observer to take notes and to use an audio recorder during the interview was received in both written and verbal formats from the nursing students. So that the students could respond freely to the questions, the interviews were held after the end of the semester during which the course was offered. Before the study was performed, ethical endorsement for the research was obtained from the Non-Invasive Research Ethics Board of the university (2020/3-18), and subsequently, permission to perform the research was received from the administration of the faculty where the research was conducted.

\section{Results}

The mean age of 23 nursing students who were included in the study was $21.35 \pm 2.3$ years, 15 students were female, 21 students were single, and 17 students had medium-level economic well-being. Three students (anxiety disorder (2) and obsessive-compulsive disorder (1)) and a member of the four students' families (depression (2), schizophrenia (1), mental retardation (1)) had psychiatric histories. Besides, 20 students stated that they could apply for mental health services if they were confronted with a mental problem. Upon the analysis of research data, five main themes and 12 sub-themes were developed. The main themes were as follows: 'meaning of the mental illness', 'challenges experienced by the patients', 'reasons for stigmatization', 'recommendations for reducing the stigmatization' and 'effect of the psychiatric nursing course' (Table 2). The main themes were successively presented below:

\section{Theme 1: Meaning of mental illness}

To assess the meaning of mental illnesses, the participant students were asked to express the concept of 'mental illness' with one word. The participants put forward words about the symptoms of the mental illnesses, the emotions felt and the situation coming into play when the mental illness was experienced.

Symptoms: $8 / 23$ of the students identified the mental illness with the symptom of the failure to think logically. Some students expressed symptoms such as asociality (5/23), and introversion (4/23).

Emotions: Fear (7/23), uneasiness (5), and unhappiness $(3 / 23)$ are the emotions which are expressed by certain students for mental illness.

Situations: To explain the mental illness, most students stated words about the situation coming into play along with the illness. These words are confinement in society $(15 / 23)$, difficulty $(7 / 23)$, difference $(5 / 23)$, unluckiness (4/23), lostness (3/23), derangement (2/23), obscurity (2/23), and innocence (2/23).

\section{Theme 2: Challenges experienced by the patients}

The challenges experienced by the individuals diagnosed with mental disorders were examined from the perspective of the participant nursing students who completed the theoretical part of the psychiatric nursing course and its practice, spent time with the patients, and provided them with care. The data were addressed under two sub-themes, namely, individual-related challenges and environment-related challenges.

Individual-related challenges: According to the participant nursing students, the patients are confronted with challenges such as the prognosis and treatment of the illness (9/23), communication problems (8/23), feelings of desperation and worthlessness $(5 / 23)$, social withdrawal (4/23), lack of self-confidence $(2 / 23)$, and feeling of hopelessness $(2 / 23)$ about the treatment of the illness. Some statements of the students were as below:

"First of all, I think it is a highly difficult process. There are several factors such as the medications which are used, the establishment of the communication, self-per-

Table 2: The main themes and sub-themes.

\begin{tabular}{|l|l|}
\hline Main themes & Sub-themes \\
\hline Meaning of mental illness & Symptoms \\
\hline & Emotions \\
\hline Challenges experienced by the patients & Situations \\
\hline & Individual-related \\
\hline Reasons for the stigmatization & Environment-related \\
\hline & Factors related to the patient/illness \\
\hline Recommendations for reducing the stigmatization & Societal factors \\
\hline & Other factors \\
\hline & Aimed at the patients \\
\hline Effect of the psychiatric nursing course & Aimed at the society \\
\hline & Aimed at the health workers \\
\hline & Emotion \\
\hline
\end{tabular}


ception, and family; and, for the person, these can serve both as the challenges and, I do not know how to say, as the triggers". (S14)

"The way the people look at them is different, they are excluded from the society, they are unhappy, and feel desperation and worthlessness". (S8)

Environment-related challenges: The lack of interest and support (10/23), stigmatization (9/23), the effect on the professional life $(6 / 3)$, exclusion from the society $(4 / 23)$, social isolation $(4 / 23)$, exposure to pressure and violence $(3 / 23)$, and confinement in the society $(3 / 23)$ were defined by participant nursing students as the challenges experienced by the patients. Some statements of the students are as follows:

"These individuals are not endowed with the opportunity to have a social setting, they are unable to perform their own professions, they are marginalized, mocked, they are treated as if they were different". (S13)

"The stigmatization is the most important one... being perceived as incompetent despite being competent, being forced to play certain roles through the exertion of pressure and the use of violence, lack of interest and obligation to be overpatient...". (S21)

\section{Theme 3: Reasons for the stigmatization}

Nursing students' views about the factors giving rise to the stigmatization of individuals with mental disorders were examined. Sub-themes and certain statements related to these factors are as follows:

Factors related to the patient/mental illness: $12 / 23$ of the students participating in the research stated that illness symptoms caused the stigma. Some students stated that the factors affecting stigmatization were the inclination to aggression (8/23), communication problems (5/23), low self-esteem (2/23), and irritability (1/23).

"Soliloquizing for reasons out of their control, being inclined to aggression, skepticism... these... that is to say, these are all related to the illness, however, other people do not perceive it that way". (S18)

"This situation can sometimes stem from the person, that is... for instance, that the person is sensitive, that the person misunderstands the situation or... that the person does not like himself/herself, that the person has low self-confidence, these all can have effect in my opinion". (S11)

Societal factors: Most students stated that the low levels of education and awareness in the society (15/23), lack of knowledge on the mental illnesses (10/23) caused the stigma. Also, students stated that not knowing the patients closely and not spending enough time together $(6 / 23)$, insufficiency of social support (5/23), insufficient empathy shown by the individuals toward the patients $(5 / 23)$, stereotypes in the society (3/23), and witnessing previously negative attitudes and behaviors toward the patients $(1 / 23)$ were the factors paving the way for the stigmatization.

"Due to the insufficiency of communication with the society, the society does not know these patients and approach them with certain biases, unfortunately". (S6)

"Ignorance, remorselessness of the society... there are certain stereotypes with origins in the past... Also observing in the past that these patients were mistreated creates a perception in the society, sets a bad example". (S22)

Other factors: Almost half of the students (12/23) put forth that showing the mental illnesses in the media in a negative context and an exaggerated manner were also among the factors leading up to the stigmatization.

"Certain people know about the mental illnesses up to the extent that the media shows them, when the media addresses them negatively and exaggeratedly... of course, the society's perception is influenced". (S23)

Theme 4: Recommendations for reducing the stigmatization

The recommendations of the participant nursing students for reducing the stigmatization related to the mental illnesses were examined. Sub-themes and some statements about this topic are as follows:

Recommendations for the patients: Some students made recommendations for the patients. Enabling the adaptation of patients to the social life $(11 / 23)$, enhancing the support $(8 / 23)$ and employment opportunities for the patients $(5 / 23)$, facilitating the recovery during the course of the illness with early diagnosis and treatment (4/23), offering training programs likely to improve the patients' self-confidence (4/23) and develop coping mechanisms and highlighting the patients' positive features (4/23) are among these recommendations.

"These people should be reintegrated into society, they must be able to perform their professions in positions convenient to them, that is... thus, they do not only feel themselves better but also the society's perspective toward them changes. They should be supported more so that they would continue their social lives". (S18)

"By being aware of the change in yourself, it is necessary to learn to live with it, in my opinion. ... Providing support to highlight the patients' qualifications, showing the patients' positive features to society, and talking about these positive features can enhance the feeling of confidence". (S1)

Recommendations for the society: All nursing students who took part in the research stressed the importance of raising the education level of the society and awareness of the society about mental illnesses. In this direction, they recommended raising the number of training programs, projects, documentaries, TV series, 
films, and public service ads (23/23). Moreover, they stated that the stigmatization would be reduced if society knew the patients closely $(10 / 23)$.

"Steps should be taken for changing the general ideas dominating the society, public service ads and TV series about the psychiatric patients can be released... that is, the society does not know these patients actual$l y$, settings and opportunities through which the society will know them closely can be created... Later on, as the society gets to know better, the biases toward them will be eliminated". (S22)

Recommendations for the health workers: A part of the participant nursing students stated that enhancing the basic communication skills of health workers $(6 / 23)$ and focusing on patient-oriented care $(4 / 23)$ could be effective in reducing stigmatization. Furthermore, a student emphasized the significance of nurses' specialization in the area.

"Health workers, in particular, should be careful, they are in this business in any case; for instance, in-service training programs can be held for promoting a more proper approach toward the patients, the nurses who are specialists in the field should work for the psychiatric service". (S5)

Other recommendations: Participant nursing students' other recommendations for reducing the stigmatization pertained to ensuring that the language used in the media in conjunction with the mental illnesses (8/23), making a therapeutic environment available in the institutions where the mental health services were offered (6/23), protecting the patients' rights $(3 / 23)$, and improving legal regulations $(3 / 23)$ would be controlled.

"Better environments should be made available, visiting the public mental health centers can be encouraged more, actually all patients must benefit from them". (S8)

"... The media shows certain incidents by exaggerating them, a control mechanism is necessary in this regard, moreover, the language which is used should be checked...". (S23)

"Legal regulations should be made, to defend the patients' rights, fines can also be raised...". (S17)

\section{Theme 5: Effects of the psychiatric nursing course}

When asked about the effect of the psychiatric nursing course, the students who partook in the research made explanations by referring comparatively to the changes experienced in their emotions, thoughts, and behaviors before and after taking the course.

Emotion: A large majority of the participant nursing students asserted that the fear and uneasiness felt before the clinical practice were alleviated (20/23), and also providing healthcare, helping and understanding the patients better gave them comfort and happiness
$(15 / 23)$. Five of the students stated that providing healthcare was tiring whilst a student said that he had an enhanced feeling of mercy. Some statements are as follows:

"I felt highly uneasy on the first day of the internship, I did not want to go to the service the following day, however, I began to get adapted later on. As I noticed that they also paid attention to me and talked with me, I felt happy. Making efforts for them, sharing their problems, accompanying them during their difficult moments are sometimes hard and tiring, however, it is also a highly special feeling". (S19)

"I felt peaceful. Being together with them, that is, helping them recover from the illness and feeling that I understood them made me happy". (S21)

"My family, namely, we, also had many challenges, I knew what type of a situation it was due to my elder brother, nevertheless, it gave rise to anger and hopelessness in me anyhow. And I never give green light to the stigmatization". (S13)

Thought: A large majority of the participant nursing students stated that knowing the patients closely by spending time with them changed the thinking that they were aggressive and it was impossible to establish communication with them (13/23). A part of the students put forth that they had a more enhanced comprehension of the importance of mental health (7/23), understood better what needs and expectations the patients had $(7 / 23)$ and that the patients were not different from other individuals (6/23), and also they had a more advanced sense about the importance of stigmatization $(5 / 23)$. Furthermore, they declared that they noticed the individual differences between the patients (4/23) and there was a transformation in their perspectives of the patients and illnesses (3/23). Some students' statements are as follows:

"It is not guaranteed that we will not have a psychiatric problem in the future. I put myself in their shoes... namely, in that way, I understood better how the stigmatization made the person feel, it is necessary to remember that they are also human beings". (S6)

"While I supposed that I understood them, observing their different sides enabled me to understand and know them better. Now, I know their needs and expectations better. It was the internship where I felt most useful". (S4)

"I explored myself, I understood how much the mental health was important". (S12)

Behavior: Virtually all participant nursing students $(19 / 23)$ asserted that the challenge and shyness experienced by them in establishing communication with the patients back in the early days declined as they got to know the patients.

"I initially feared and shied away from the patients as I was afraid that they would probably harm me... how- 
ever, later, as I talked to them, I understood that they were not that harmful, and I could comfortably go and talk to them". (S15)

\section{Discussion}

In this study, by holding interviews with nursing students who completed the theoretical part of the psychiatric nursing course and its clinical practice, nursing students' views about mental disorders and stigmatization were examined.

When the participant nursing students were asked about the meaning of mental illness, most of them referred to the words such as confinement, challenge, difference, failure to think logically, asociality, fear, and unhappiness. It is stated that the society in Turkey in general had negative beliefs and attitudes toward psychiatric patients/mental illnesses [3]. As the participant nursing students are also members of the society, it is natural that their responses are in a similar vein to those of society. On the other hand, more positive and emphatic responses given by the participant nursing students vis-à-vis the society can be associated with having close contact with the patients and observing their lives by spending time with them.

A large majority of the participant nursing students said that the biggest challenge experienced by the patients was the stigmatization, and additionally, attention and support were also lacking. Some students stated that the patients were challenged concerning the prognosis and treatment of the illness and the establishment of communication, and had feelings of low self-esteem, desperation, worthlessness, and hopelessness. It was ascertained that no other study analyzed the nursing students' views about the challenges experienced by individuals with mental illnesses. The statements made by the students can be considered as indicators of the societal and inner stigmatization felt by the patients [23]. In a qualitative study performed with the schizophrenic patients and their families for analyzing the stigmatization experience, the following two themes were underlined: 'being socially rejected', namely, the case in which others do not want to establish communication and live with the patient and his/her family and do stay away from them in fear, and 'being oppressed by others', namely, the case in which others behave aggressively toward the patient and his/ her family, violate their rights, and mock them through insults at them with inaccurate judgments [24]. The two themes referred to in the aforementioned study conform to the sub-themes in this current study. [25]. Also in the previous studies performed with the patients, it was found that the patients were confronted with discrimination, social withdrawal, alienation, and self-stigmatization [25,26], and self-esteem and social support were associated with self-stigmatization [27], and the patients had difficulties in the professional life owing to the stigmatization [28]. It can be asserted that the students who had the opportunity in the areas of practice in the context of psychiatric nursing course to know the patients closely, to observe them, to establish communication with them, to witness or listen to the challenges experienced by them had awareness about the challenges encountered by the patients in the social life and the negative perceptions toward them.

In this study, as the reasons for stigmatization relevant to the mental illnesses, a large segment of the participant nursing students referred to the societal factors such as low levels of education and awareness in the society, not knowing the patients closely, lack of social support and presence of stereotypes. Also, in a qualitative study performed with nursing students, the students underlined the societal value judgments and society's characteristics, social support systems, and the state of familiarity and contact as the factors influencing the stigmatization [29]. Moreover, another finding of the study is that the students put forward also the illness symptoms, the inclination to aggression, and communication problems as the factors affecting the stigmatization. The changes which can be observed with naked eyes in the speech and behaviors are the indications which are identified most frequently with mental illnesses and result in the development of certain negative attitudes toward the individuals in the society [30]. Furthermore, participant nursing students talked about the negative effects of the media. Also in the relevant literature, it is asserted that the media presented the mentally ill people as being inclined to aggression, unpredictable, harmful, and worthless, and hence contributed to the stigmatization of the mental illnesses [31]. In this current study, the participant nursing students set forth that the irritability and low self-esteem felt by the patients could be among the factors affecting the stigmatization. Also in the other study, the patients' characteristics related to self-perception were highlighted by the students about the stigmatization [29]. It can be asserted that the findings of this current study are compatible with the relevant literature.

In the study, all nursing students talked about the necessity of the measures to be taken for society. According to the participant nursing students, providing training programs and applications which will enhance the awareness level and knowledge base of the society and extending the opportunity to get to know the patients closely are the most important and essential initiatives to reduce the stigmatization. The study by Rüsch, et al. (2005) mentioned about three main strategies in the fight against stigmatization, namely, protesting, training, and contacting [32]. It can be asserted that the participant nursing students' recommendations were multifaceted and in conformity with the relevant literature. Moreover, approximately half of the students underlined the necessity of strengthening the patients, enabling them to adapt to the social life, organizing training programs which would enhance self-con- 
fidence and develop coping mechanisms, and highlighting the positive features. Stigma resistance which refers to the individual's capacity to stand up against the stigmatization and to remain unaffected by it is effective in the fight against the stigmatization. To enhance the stigma resistance, it is important that the patients accept mental health stereotypes, be able to make positive reinterpretations, use effective coping strategies, and have higher levels of self-esteem [33-35]. In this sense, it can be considered that the students made recommendations that would enhance the patient's stigma resistance. Furthermore, in the study, some students made recommendations such as ensuring that those providing healthcare service got specialized and their attitudes toward the patients would be improved, increasing the social support, making the necessary legal regulations, and controlling the media. Likewise, in the relevant literature, there are recommendations in support of the participant students' views [3,32,36-38]. It can be asserted that the nursing students achieved in making recommendations concerning the reasons for the stigmatization and had high-level awareness about the stigmatization.

Most participant nursing students said that the fear and uneasiness which they felt at the outset of the clinical practice were alleviated as they got to know the patients closely, and as the time went by, they stopped thinking that the patients were aggressive and dangerous, felt more comfortable in establishing communication with the patients, and their perceptions about the mental illnesses changed. Other research studies also indicate that the students perceived individuals with mental disorders as less dangerous following the clinical practice $[39,40]$. In a qualitative study carried out in South Korea with nursing students, it was put forth that, in the context of psychiatric nursing, the students had emotional fluctuations and burnout at the beginning of the clinical practice whereas they experienced transformation and growth at the end of the clinical practice [41]. Also in some studies performed previously, it was found that the student nurses who took the psychiatric nursing course, spent time with the patients, or got in touch with standard patients through simulation method had a more positive attitude to the issue of stigmatization [29,42-45]. In another study, the nursing students stated that, at the end of the clinical practice, the stigmatization related to the mental illness was reduced by virtue of the empathy felt along with the development of therapeutic relations, and the communication occupied a very important place [46]. The findings of this current study share similarities with the results of most studies in the relevant literature. However, there are also studies which set forth that theoretical and practical education programs were not sufficiently effective in changing the students' beliefs and attitudes $[42,47]$. This difference in the findings can be connected with the properties of the clinical setting, duration of the clinical practice, the intensity of the experience, and student-related factors.

\section{Limitations}

As it is a study performed with a qualitative method, the research findings cannot be generalized to other research studies. Therefore, the study results cover solely the students who agreed to participate in the research and took the course on mental health and mental illnesses.

This study recruited students from a single nursing school, findings should be taken into account in this context and cannot be generalized to all nursing students. Students may have reported their views based on preferred assumptions or acceptable experiences. Future research may include integrated qualitative and quantitative data from a mixed method study.

\section{Conclusion and Recommendations}

In this study, the nursing students who took a psychiatric nursing course described the mental illness with words that referred to the illness symptoms and the situation and emotions created by the illness. Moreover, they defined a high number of individual-related and environment-related challenges. Among these challenges, stigmatization was the one emphasized most frequently by the students. The students made recommendations concerning the reasons for the stigmatization. In conclusion, it was found that the nursing students had common views about the mental illness and the reasons and recommendations for the stigmatization, and the psychiatric nursing course gave rise to positive changes in the feelings, thoughts, and behaviors related to the mental illnesses. Identifying what views the students who are prospective nurses have about the fight against mental disorders and stigmatization will guide the way for the development of nursing curriculum and nursing practices. Moreover, it will make contributions to the enhancement of quality and satisfaction in patient care in the long run. In raising the awareness of the students about mental illnesses and stigmatization and developing their therapeutic communication skills, the clinical practice occupies a highly crucial place in the curriculum. It is recommended that the nursing instructors use the study results in guiding the nursing students willing to work in this field in the future and also in developing the curriculum.

\section{Acknowledgement}

I would like to thank the nursing students who participated in this study for their contribution.

\section{Conflicts of Interest}

The author declared that no conflict of interest.

\section{Author Contributions}

$\mathrm{CB}$ conceived the study and determined the method- 
ology. CB collected and analyzed the data. CB took the lead in writing and organizing the manuscript.

\section{Ethical Approval}

Non-Invasive Research Ethics Board of the university approval was obtained (2020/3-18).

\section{References}

1. Ellison N, Mason O, Scior K (2013) Bipolar disorder and stigma: A systematic review of the literature. J Affect Disord 151: $805-820$

2. Thornicroft G, Brohan E, Rose D, Sartorius N, Leese M, et al. (2009) Global pattern of experienced and anticipated discrimination against people with schizophrenia: A cross-sectional survey. Lancet 373: 408-415.

3. Cam, A Bilge (2013) The process of stigmatization, attitude, and belief about mental illness and patient in Turkey: A systematic review. J Psychiatr Nurs 4: 91-102.

4. World Health Organization (2013) The World Health Report 2001-Mental Health: New Understanding, New Hope, Geneva, Switzerland.

5. Link BG, Phelan JC (2013) Labeling and stigma. In: Aneshensel CS, Phelan JC, Handbook of the Sociology of Mental Health. ( $2^{\text {nd }}$ edn), Springer, Dordrecht, 525-541.

6. Stuber JP, Rocha A, Christian A, Link BG (2014) Conceptions of mental illness: Attitudes of mental health professionals and the general public. Psychiatr Serv 65: 490-497.

7. Arkan B, Bademli K, Çetinkaya Duman Z (2011) Attitudes of health professionals towards mental disorders: Studies in Turkey during the last decade. Curr Approaches Psychiatry 3: 214-231.

8. Reavley NJ, Mackinnon AJ, Morgan AJ, Jorm AF (2014) Stigmatising attitudes towards people with mental disorders: A comparison of Australian health professionals with the general community. Aust N Z J Psychiatry 48: 433-441.

9. Çam, Baysan Arabaci L (2014) The nurses beliefs toward mental illnesses working in regional psychiatric hospital and affecting factors. Türkiye Klin J Nurs Sci 6: 13-25.

10. Fokuo JK, Goldrick V, Rossetti J, Wahlstrom C, Kundert C, et al. (2017) Decreasing the stigma of mental illness through a student-nurse mentoring program: A qualitative study. Community Ment Health J 53: 257-265.

11. Ordan R, Shor R, Liebergall-Wischnitzer M, Noble L, Noble A (2018) Nurses' professional stigma and attitudes towards postpartum women with severe mental illness. J Clin Nurs 27: 1543-1551.

12. Robson D, Haddad M, Gray R, Gournay K (2013) Mental health nursing and physical health care: A cross-sectional study of nurses' attitudes, practice, and perceived training needs for the physical health care of people with severe mental illness. Int J Ment Health Nurs 22: 409-417.

13. Kameg K, Mitchell AM, Clochesy J, Howard VM, Suresky $\mathrm{J}$ (2009) Communication and human patient simulation in psychiatric nursing. Issues Ment Health Nurs 30: 503-508.

14. Samari E, Seow E, Chua BY, Ong HL, Abdin E, et al. (2018) Stigma towards people with mental disorders: Perspectives of nursing students. Arch Psychiatr Nurs 32: 802-808.

15. Foster K, Withers E, Blanco T, Lupson C, Steele M, et al. (2019) Undergraduate nursing students' stigma and recovery attitudes during mental health clinical placement: A pre/posttest survey study. Int J Ment Health Nurs 28: 1065-1077.
16. Creswell JW, Poth CN (2018) Qualitative inquiry and research design: Choosing among five approaches. ( $5^{\text {th }}$ edn), Sage Publications, Thousand Oaks.

17. Tong A, Sainsbury P, Craig J (2007) Consolidated criteria for reporting qualitative research (COREQ): A 32-item checklist for interviews and focus groups. Int J Qual Heal Care 19: 349-357.

18. Yildirim A, Şimşek H (2013) Sosyal bilimlerde nitel araştirma yöntemleri (Qualitative research methods in the social sciences). ( $9^{\text {th }}$ edn), Seçkin Yayincilik, Ankara.

19. Cooke A, Smith D, Booth A (2012) Beyond PICO: The SPIDER tool for qualitative evidence synthesis. Qual Health Res 22: 1435-1443.

20. Erdoğan S, Nahcivan N, Nihal MN (2014) Hemşirelikte araştırma süreç, uygulama ve kritik [Nursing research. Process, implementation, and critics]. Nobel Publication, Ankara.

21. Noble H, Smith J (2015) Issues of validity and reliability in qualitative research. Evid Based Nurs 18: 34-35.

22. Miles MB, Huberman AM (1994) Qualitative data analysis. SAGE Publications, International Educational and Professional Publisher, Thousand Oaks, London, New Delhi.

23. Corrigan $P$ (2004) How stigma interferes with mental health care. Am Psychol 59: 614-625.

24. Rezayat F, Mohammadi E, Fallahi-khoshknab M, Sharifi V (2019) Experience and the meaning of stigma in patients with schizophrenia spectrum disorders and their families: A qualitative study. Jpn J Nurs Sci 16: 62-70.

25. Lv Y, Wolf A, Wang X (2013) Experienced stigma and self-stigma in Chinese patients with schizophrenia. Gen Hosp Psychiatry 35: 83-88.

26. Brohan E, Elgie R, Sartorius N, Thornicroft G, GAMIAN-Europe Study Group (2010) Self-stigma, empowerment and perceived discrimination among people with schizophrenia in 14 European countries: The GAMIAN-Europe study. Schizophr Res 122: 232-238.

27. Mohamed AA (2019) Internalized stigma of mental illness and its relation with self-esteem and social support among psychiatric patients. Evidence-Based Nurs Res 1: 15-25.

28. Işik I, Savaş G, Kiliç N (2019) The difficulties that individuals with schizophrenia face in business life. Acibadem Univ Heal Sci J 10: 399-408.

29. Büyükbayram A, Baysan Arabaci L, Taş G, Kurt A (2020) The opinions of nursing students who have taken and not taken the psychiatric nursing courses towards psychiatric stigma. Izmir Katip Celeb Univ Fac Heal Sci J 5: 263-275.

30. Bahar A (2007) Şizofreni ve damgalama. Firat Sağlik Hizmetleri Derg 2: 101-110.

31. Asan Ö (2019) Mental illnesses and stigmatization; inside community, press, health professionals and everywhere. Sak Tip Derg 9: 199-205.

32. Rüsch N, Angermeyer MC, Corrigan PW (2005) Mental illness stigma: Concepts, consequences, and initiatives to reduce stigma. Eur Psychiatry 20: 529-539.

33. Lien YJ, Kao YC, Liu YP, Chang HA, Tzeng NS, et al. (2015) Internalized stigma and stigma resistance among patients with mental illness in Han Chinese population. Psychiatr $Q$ 86: 181-197.

34. Kao YC, Lien YJ, Chang HA, Tzeng NS, Yeh CB, et al. (2017) Stigma resistance in stable schizophrenia: The relative contributions of stereotype endorsement, self-reflection, self-esteem, and coping styles. Can J Psychiatry 62: 735-744. 
35. Nabors LM, Yanos PT, Roe D, Hasson-Ohayon I, Leonhardt BL, et al. (2014) Stereotype endorsement, metacognitive capacity, and self-esteem as predictors of stigma resistance in persons with schizophrenia. Compr Psychiatry 55: 792-798.

36. Pinto-Foltz MD, Logsdon MC (2009) Reducing stigma related to mental disorders: Initiatives, interventions, and recommendations for nursing. Arch Psychiatr Nurs 23: 32-40.

37. Chronister J, Chou CC, Liao HY (2013) The role of stigma coping and social support in mediating the effect of societal stigma on internalized stigma, mental health recovery, and quality of life among people with serious mental illness. J Community Psychol 41: 582-600.

38. Rossi A, Cetrano G, Pertile R, Rabbi L, Donisi V, et al. (2012) Burnout, compassion fatigue, and compassion satisfaction among staff in community-based mental health services. Psychiatry Res 200: 933-938.

39. Grav S, Juul EML, Hellzén O (2010) Undergraduate nursing student experiences of their mental health clinical placement. Nord J Nurs Res 30: 4-8.

40. Alshowkan AA, Mohamed N, Kamel F (2016) Nursing student experiences of psychiatric clinical practice: A qualitative study. J Nurs Heal Sci 5: 60-67.
41. Cha S, Moon H, Park E (2020) Korean nursing students' first experiences of clinical practice in psychiatric nursing: A phenomenological study. Healthcare (Basel) 8: 215.

42. Günay S, Bekitkol T, Ekitli BG, Yildirim S (2016) Determination of the mental disorder beliefs of students in a nursing faculty. J Psychiatr Nurs 7: 129-134.

43. Sarikoç G, Özcan TC, Elçin M (2016) An innovative practice in psychiatric nursing education: Standardized patients. Dokuz Eylul Univ E-Journal Nurs Fac 9: 61-66.

44. Abuhammad S, Hatamleh R, Howard K, Ahmad MM (2019) Correlates and predictors of stigmatization of patients with mental illness among nursing students. J Psychosoc Nurs Ment Health Serv 57: 43-51.

45. Duman ZÇ, Günüşen NP (2017) Effects of the psychiatric nursing course on students' attitudes towards mental Innesses, perceptions of psychiatric nursing and career choices. Turkiye Klin J Nurs 9: 255-264.

46. Demir S, Ercan F (2018) The first clinical practice experiences of psychiatric nursing students: A phenomenological study. Nurse Educ Today 61: 146-152.

47. Şahin G, Amancali M, Sayin AS, Yakar A, Buzlu S (2019) Undergraduate nursing students' attitudes towards patients with mental disorders and related factors. Acibadem Univ Heal Sci J 10: 218-224. 